\section{Solution Chemistry}

by Pal Sipos

The $3^{\text {th }}$ International Conference on Solution Chemistry (ICSC2018) was organized by the Hungarian Chemical Society and was held in the Hunguest Hotel Forrás in Szeged, Hungary, 26-30 August 2018. The ICSC2018 is a continuation of the successful IUPAC conference series that began in Lund, Sweden in 1988. The conference brought together scientists from all branches of solution chemistry, including both fundamental and applied sciences. The topics of the conference included many themes associated with modern applications of solutions: in the medical sciences; for practical/industrial purposes; radioactive waste management; spectroscopy; (bio)coordination chemistry; supercritical fluids; colloids and interfaces; ionic liquids; and computational studies, as well as more traditional work in thermodynamics and solubility phenomena.

The Conference had more than a hundred registered participants, with every continent represented. The 12 invited lecturers gave 6 plenary and 6 keynote talks, all of a very high standard. They were as follows:

- K. N. Raymond, University of California, Berkeley, USA; Solution thermodynamic and kinetic studies of host/guest supramolecular clusters

- I. Persson, Swedish University of Agricultural Sciences, Uppsala, Sweden; Solution chemistry in the surface region of aqueous solutions

- A. Skerencak-Frech, Karlsruhe Institute of Technology, Institute of Nuclear Waste Disposal, Karlsruhe, Germany; Radionuclide chemistry in Nuclear Waste Disposal-application of modern spectroscopy for molecular process understanding and actinide thermodynamics

- S. Hirofumi, Kyoto University, Kyoto, Japan; Theoretical study of chemical reactions in solution phase using a variety of theoretical approaches

- S. P. Rosenberg, Emirates Global Alumina, Dubai, United Arab Emirates; The importance of solution chemistry in industrial hydrometallurgy

- P. Tremaine, University of Guelph, Guelph, Canada; Formation constants and transport properties of aqueous complexes in hydrothermal solutions by Raman spectroscopy and AC conductivity methods

- É. A. Enyedy, University of Szeged, Szeged, Hungary; Solution chemistry of anticancer metallodrugs and their interaction with proteins

- Z. Yu, Tsinghua University, Beijing, People's Republic of China, Excess spectroscopy, a new approach to study the structures of liquid mixtures
- J. Hunger, Max Planck Institute for Polymer Research, Mainz, Germany; Interaction and dynamics of organo-catalysts in solution

- M. Kanakubo, National Institute of Advanced Industrial Science and Technology, Sendai, Japan; Supercritical fluids, ionic liquids, and their applications

- G. Laurenczy, École Polytechnique Fédérale de Lausanne, Lausanne, Switzerland; Practical applications of solution chemistry in energy storage and $\mathrm{CO}_{2}$ utilization

- Gy. Tircsó, University of Debrecen, Debrecen, Hungary; MRl imaging and solution chemistry.

In addition, 40 section lectures and 40 posters were presented. Glenn Hefter, the IUPAC representative to ICSC2018, gave a 10-minute talk detailing the various activities of IUPAC. Following the poster session, Earle Waghorne presented two poster prizes, sponsored by SPRINGER, to Sándor Nagy (University of Debrecen, Hungary) and to Kazuyoshi Kaneko (Soka University,

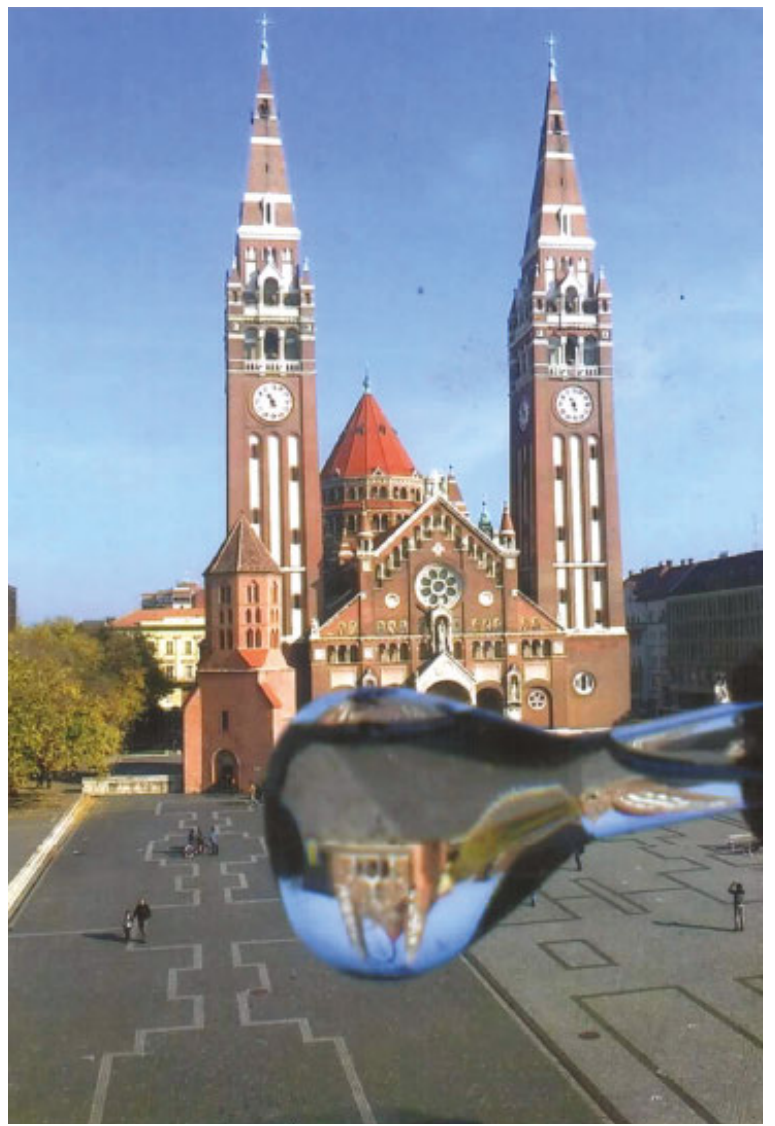

A view of the Votive Church in Szeged through a volumetric flask containing a solution, the official logo of the ICSC2018. (Photo by G. Kiss) 
Japan). Four further posters were given Honorable Mention certificates, reflecting the high standard of the presentations.

During the conference, Ingmar Persson retired from the chairmanship of the International Steering Committee. To honor his chairmanship (2001-2018), he was presented with a bottle of Tokaji wine, vintage 2001, at the conference banquet. Professor Persson is replaced by Toshio Yamaguchi, whose mandate will expire in 2025. The next ICSC, the $36^{\text {th }}$, will be held in 2019 in Xining, China. The organizers gave a presentation and demonstrated that all the necessary preparations are well underway. The International Steering Committee selected Cartagena, Columbia to organize the $37^{\text {th }}$ ICSC in 2021, which will see the ICSC return to its customary biennial timing.

Beyond the busy scientific schedule, the conference was rich in social events. The opening ceremony was held in the Szeged Town Hall, sponsored by the City Council. An organ concert was organized at the famous Votive Church one evening. Conference excursions included a visit to the National Memorial Park and outdoor village museum in Ópusztaszer. The closing banquet included a wine tasting, featuring local winemaker, Sándor Somodi.

Thus, the $35^{\text {th }}$ ICSC was successful on several fronts: high quality science and interesting social programs. Special thanks go to the organisers from the Hungarian Chemical Society (especially Beáta Androsits, Beatrix Schenker, and Eszter Körtvélyessy) and to the contributing members of the Materials and Solution Structure Research Group (MASOST) at Szeged: Csilla Dudás, Eszter Orbán, Dr. Bence Kutus, Szilveszter Ziegenheim, and Ákos Buckó.

We look forward to meeting again in Xining, in 2019 !

Pal Sipos<sipos@chem.u-szeged.hu> is chairman of the Local Organizing Committee.

\section{Organometallic Chemistry and Challenges in $\mathrm{CO}_{2}$ Activation and Utilization}

by Luca Gonsalvi, Alessandro Mordini, and Maurizio Peruzzini

The XXVIII International Conference on Organometallic Chemistry (ICOMC 2018) was held in Florence, ItaIy, from 15-20 July 2018. ICOMC 2018 is the $28^{\text {th }}$ edition of a series biennial events that came back to Italy after exactly 30 years (Torino 1988), and was organized

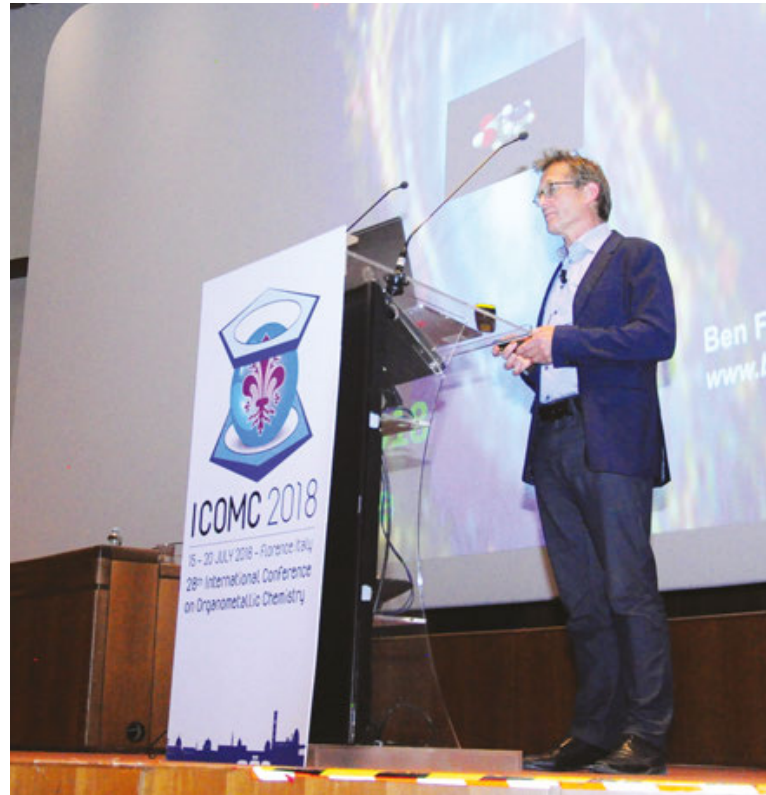

Ben L. Feringa's Plenary Lecture, Thursday 19 July 2018

by the Institute of Chemistry of Organometallic Compounds (ICCOM) of the National Research Council of Italy (CNR). The Organizing Committee was formed by the Chair Dr. Maurizio Peruzzini (CNR Research Director), the Co-chair Dr. Alessandro Mordini (CNR Research Director), and the Scientific Secretary, Dr. Luca Gonsalvi (CNR Senior Researcher). A Professional Conference Organizer (PCO), Adria Congrex s.r.l., was in charge of the overall management and logistics of the event, including the official ICOMC 2018 website (www.icomc2018. com). More than 30 ICCOM students and staff personnel, including full-time researchers, also gave valuable contributions before and during the event.

The Conference venue was the Florence Congress \& Exhibition Center, located in a beautiful park in the historical city center; the venue was in close proximity to Santa Maria Novella church and a nearby railway station. The ambitious goal of the 2018 edition was to be one of the main meeting points for scientists active in various fields of organometallic chemistry worldwide for the year, attracting both inorganic and organic chemists due to the interdisciplinary nature of this research area. The scientific program was organized as lecture and poster parallel sessions, focusing on the most recent scientific advances in key and emerging areas of organometallic chemistry including:

- asymmetrics synthesis by organometallics

- bio-organometallic and medicinal chemistry

- clusters, coordination polymers, and metalorganic frameworks (MOFs) 